\title{
transUrban: Vauban
}

\author{
T. Schroepfer ${ }^{1}$, L. Hee ${ }^{2}$ \& C. Werthmann ${ }^{3}$ \\ ${ }^{I}$ Department of Architecture, Graduate School of Design, \\ Harvard University, USA \\ ${ }^{2}$ Department of Architecture, National University of Singapore, \\ Singapore \\ ${ }^{3}$ Department of Landscape Architecture, Graduate School of Design, \\ Harvard University, USA
}

\begin{abstract}
transUrban is an ambitious project that attempts to chart design ideals, ideas, and processes of recent and current experiments for cities of the future. The idea of sustainable cities is examined here in more than the environmental and ecological aspects, and the emergent forms of urbanism documented and analyzed for lessons that inform on the shape of cities to come. These built experiments embody complex topics of design, dwelling, community in space, building technologies, environmental strategies, as well as models of affordability, but at the same time, explore new trajectories in the development of the city. Topographies of change re-contour the forms of urbanism as we know it, and do not conform to a generic type, but create in concert a shift of paradigms. The patterns that emerge reveal complexity and integrated thinking across disciplines. transUrban charts this terrain to find applicable design strategies for the future. Vauban, the topic of this paper and the first in a series of case studies, describes the guiding urbanism principles and their implementation in the planning and design of a new major development of a sustainable city district: a 38-hectare former barracks site near the town center of Freiburg, Germany that was purchased by the city in 1994 with the goal to convert it into a flagship environmental and social project. Vauban comprises 2,000 homes to house 5,000 people, as well as business units to provide about 500-600 jobs. The project is currently nearing completion and is widely seen as one of the most positive examples in Europe of environmental thinking in relation to urban design.
\end{abstract}

Keywords: environmentalism, sustainable architecture, sustainable urbanism. 


\section{Introduction}

\subsection{Context}

Freiburg, a university town in the southwest of Germany has a young and motivated population, and with some twenty years of environmentally sensitive policies and practices, it has often been called the European capital of environmentalism. The purchase of Vauban, a former French barrack quarter, which was used from post-WWII to German Reunification, presented the excellent opportunity for the city to build a flagship environmental city quarter with a vibrant social mix. The project was to be completed in three phases between 1998 and 2006 .

The city's environmental leadership was apparent already in the mid-1980s, when city authorities in co-operation drew up a rational energy plan for the city with regional energy and water companies. By the 90s, two regional schemes were in place for citizens' active participation in sustainable development principles. In 1996, an environmental protection plan to reduce $\mathrm{CO}_{2}$-emission by $25 \%$ by year 2010 was put in place by the City Council.

To date, Freiburg enjoys a well-developed public transportation system that gives pedestrians and cyclists priority on the roads and where half the journeys in the city are made on bicycles, household waste sorting and recycling and widespread use of solar energy has long been part of daily life in the city. As a positive impact on the city's economy, more than 10,000 jobs are created in the fast-growing environmental sector, based on the combined efforts of businesses, the university and municipal authorities. The city also houses the headquarters of Solarfabrik, one of Germany's largest solar paneling manufacturers, and the Fraunhofer Institute for Applied Research into Solar Energy. A wide-ranging program entitled "Freiburg - Solar City" was exhibited at the Hanover EXPO in 2000 .

\subsection{The Vauban Quarter}

Following the fall of the Berlin Wall in August 1992, French troops stationed at Freiburg, Germany vacated the barrack quarter known after WWII as Vauban. In 1994, the city purchased the 38-hectare site from the Federal State, and by 1995 , a decision was made to convert this into a flagship environmental and social project. The main aims of the project were to achieve:

- a good mix of housing and workplaces;

- alternative modes of transport - by foot, bicycle or public transportation instead of cars;

- preservation of existing mature trees and the protection of the green area in the environs of an adjacent stream;

- balanced relationship between external and internal spaces;

- low-energy buildings.

Three phases were planned for implementation between 1998 and 2006, and comprised 2000 homes for a population of 5000, plus small businesses to provide 500 to 600 jobs within the quarter [1]. 


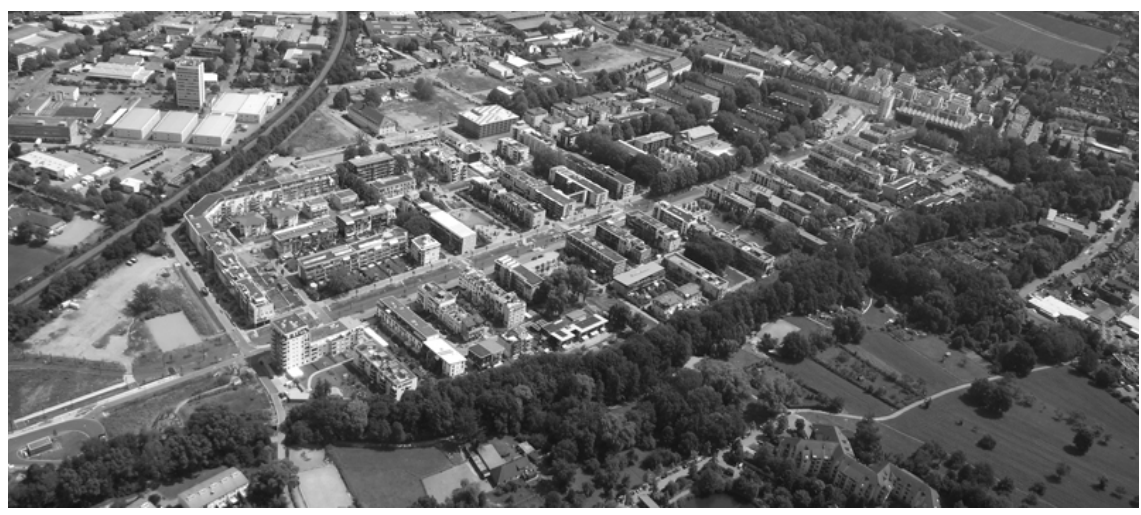

Figure 1: Aerial photograph of Vauban July 2006, source: authors' own.

\section{Ideas and ideals}

In 1996, the proposal for Vauban was presented as a best German practice on HABITAT II, the United Nations Conference on Human Settlements, in Istanbul, Turkey. Between 1997 and 1999, LIFE, the European Union's financial instrument for the environment, supported the project under the title "Realization of the Sustainable Model District Vauban" [2]. In 1999, the Deutsche Bundesstiftung Umwelt (German Federal Foundation for the Environment) funded an international conference on sustainable urban development under the title "UrbanVisions". Forum Vauban and ICLEI, the International Council for Local Environmental Initiatives, organized the conference that included over 100 participants from 21 European countries. UrbanVisions was a preparatory event for Urban 21, a global conference on the urban future that took place in Berlin, Germany in 2000. UrbanVisions culminated in the publication of a document with ten theses for sustainable urban development [3]. The following sums up main ideas and ideals for Vauban: [4].

Diversity in place - A community to be created in place by achieving a good mix of demographic groups, cutting through different generations, work, culture and abilities - the new, inclusive city quarter is envisioned to comprise privatelyfinanced homes mixed with social housing, without any groups being singledout. Spaces created here would be free and accessible to all, regardless of status and age - an open-invitation for new encounters and experience.

Design by choice - Allotment of small parcels to be developed by different architects working with different client groups allowed for a plethora of design solutions based on simple guidelines set by the city authorities. The "democratization" of design enables multiple built solutions developed from the ground-up instead of the top-down planning model, encouraging a sense of ownership and shared responsibility in developing the form of the community. Mixed-use neighborhoods incorporating public and private buildings and institutions remove the deadening effects of functional zoning. 
Self-organizing communities - The integrative approach to shaping the form of the city quarter works through innovative processes and embody an interdisciplinary approach. The involvement of the community in the development process strengthens communal bonds and encourages shared goals and responsibilities as well as variety and identity to the built form. By articulating their needs and expectations, the community is formed in space even before the first building is erected. Such a participatory model also allows for cumulative intelligence to be gained through self-organizing processes of "learning-by-doing" - experimenting with ideas as the community takes shape.

Open-ended development - New layouts that allow for openness for a multitude of uses through flexible planning and design make room for changes in family type, size and composition in the future. The design and layouts of public amenities and institutions are intended to accommodate changing social needs as the community matures.

Public Space - Good public spaces at different scales would be created with a strong emphasis on public safety through the design and layouts of these spaces. By constituting hierarchies of public, semi-public and private residential spaces through clustering these with public amenities, streets and neighborhood layouts, with a good visibility of such spaces, new public spaces form an important community asset to the development of the city quarter. These spaces form the backbone of the new city quarter - as meeting spaces for discussions and new encounters and experiences.

Environmental Urbanism - Clear guidelines for the development of the new city quarter would favor environmentally-friendly urbanism a new reality - car-free neighborhoods as far as possible both through removing the need for automobiles as well as restrictions to car-parking. Public space would take precedence over space for cars, and the streets returned to people and for public transport and bicycles. Reasonable restrictions are imposed regarding carownership and garaging. Ecologically responsible energy concepts would be implemented through low energy standards, the use of renewable energy sources, resource-conservation and recycling.

Reclaiming Mobility - The concept of mobility is to be reclaimed - by enabling people to be freed from the necessity of relying on cars for transport. Tramlines would form the backbone of public transportation linking the new city quarter with the rest of the city. For local travel, amenities and public institutions would be located within walking distance. It is envisioned that streets would once again become public spaces - returned to children, pedestrians and bicycles, being freed of curbside parking and with only limited traffic. Safe, bicycle-friendly design would encourage their usage such that trips on bicycles would form the bulk of local traffic. 


\section{Tools and implementation}

The ideas and ideals for Vauban had to be made into comprehensive policies, regulations and initiatives that would lead to the desired results, as well as the formation of citizens' groups empowered to reify the goals of such a development. The following summarizes the implementation tools for the development of the Vauban quarter:

\subsection{Processes}

Building regulations - the Freiburg city authorities had been able to achieve their environmental and social aims through planning regulations and conditions for the sale of individual plots. These included increased building density, social and functional mixes, flat roof greening, and rainwater disposal within the building boundaries. The requirements for Vauban further some of these aims, some more stringent than national requirements.

Building co-operation - a large part of the success of the Vauban development could be attributed to the ground-up community planning process facilitated by non-profit organizations that initiated public participation that went far beyond what was legally required. The extended citizen participation in Vauban led to a large number of workshops in that participants discussed topics like designing residential streets, green spaces and energy consumption that often led to suggestions, which were presented to the official planners and often became part of the planning and design of the new district.

Community building - the implementation of joint building projects and public participation helped to forge a mix of residential buildings and workplaces. Community relations were built even before physical building. In an attempt to determine a heterogeneous community, a model called the Blockprofil (block profile) was developed along categories of resident types in terms of martial status, number of children, occupation, etc, to ensure that the desired diversity was fulfilled.

Programs - Vauban houses its population not only in new buildings, but also included the use of some renovated barrack buildings as student housing, an asylum-seekers' center and functions to service the quarter, such as schools, shops and various offices related to the new city quarter.

\subsection{Mobility}

Mobility concept - Vauban is designed to reduce the need for car-use and to cut overall journey distance. The compactness of the development reduces the need to use a car between home, workplace, school and amenities, while tram and bus stops are placed not more than $500 \mathrm{~m}$ from buildings in the neighborhood. The car parking garages located at the edge of the development support the creation of car-free Vauban - car access is limited and restricted to the main access road. Actual car-ownership in Vauban is $80 \%$ lower than in the rest of the city. 


\subsection{Spatial concept}

Traffic infrastructure and public space - in car-reduced Vauban, the streets are taken over by a multitude of public functions besides being access roads. On the development's main tree-lined thoroughfare that links the quarter to the city, the street is bounded by a footpath-cum-cycle track, which buffers the housing developments and community gardens. There is a speed limit of $30 \mathrm{~km} / \mathrm{h}$ on the main thoroughfare, while the side access roads have a limit of $10 \mathrm{~km} / \mathrm{h}$ and are no-parking zones, aside for set-downs and deliveries. As such, they take on the function of "communication spaces" or "urban courtyards". The main public square of the quarter is surrounded by shops, offices, medical facilities and cafes. Other types of public spaces include the arcade spaces created by lifting apartments above ground floor businesses and retail units and are fronted by a short-term parking area. The north- and south-end of the quarter have streets, which are entirely residential and have a lush quiet ambience.

Green spaces - Existing trees had to be included in the layout for Vauban. The vegetation of an existing creek was made a conservation area. The new district has a calculated mix of open public "green corridors" and private green spaces. Three green corridors connect the creek area with the new district in the North.

\subsection{Environmental measures}

Building regulations - In the new quarter, all buildings must meet the low energy house requirements of an annual heating energy consumption $65 \mathrm{kWh} / \mathrm{m}^{2}$ or less. Also included in the development are houses designed as passive houses that are oriented north to south and unobstructed by adjacent plus-energy buildings and that produce $15 \mathrm{~kW} / \mathrm{m}^{2}$ per year. Other houses are powered by a wood-chip powered plant, which is considered a renewable and carbon-neutral source of energy.

\section{Critique}

The substantiation of ideas from stated ideals to policies and tools for implementation for the Vauban project illustrate in many ways on a micro-scale how an experiment in sustainable urban development can be implemented. The project history of Vauban illustrates the complexities of environmental city planning and design. We would argue that the ambition to make Vauban not just another example of sustainable building but to address sustainability on a city scale is what makes it a unique project.

However, it is often said that the proof of the pudding is in the eating, and so we would like to conclude by evaluating the Vauban project as it is built against the ideas and ideals embodied in its inception. Such an analysis also points out possible conflicts that some of these ideals present when implemented as a whole. For the sake of the discussion, we have condensed the ideals in four thematic areas that raise questions of idea versus actual form but we would like 
to point out that this discussion is still open-ended as many of my observations may have to be quantitatively verified to be used as actual data:

\subsection{Community}

That Vauban was conceived on the site of former French Army barrack grounds government allowed for an experimental community on grounds which in parts offered almost a tabula rasa condition. Such a condition both afforded innovation, but to some degree, detachment from the surrounding environs of Freiburg. It is also unclear how well the work-live environment expressed in the brief for Vauban has come to fruition. The employment opportunities within the quarter are few, consisting mainly of operators of the small retail outlets, services providers such as cafes, schools, and limited number of small offices. The adjacent communities may add to the conviviality of Vauban's town center, but it remains to be seen if these communities form networks.

The pluralistic communities mentioned in the ideals translate in the actual quarter to a population that seemed composed of young married couples, middleclass white-collared workers, especially of selected professional fields such as those related to the design industry, college students and those who share the similar progressive mindsets. About $17 \%$ of Vauban's current population is under the age of 17. Such a demographic also creates demands for amenities for children and teenager, which might become obsolete once this clustered demographic age-group outgrows these facilities. It is a rare sight in Vauban to see older persons, or those from more diverse racial and occupational backgrounds.

\subsection{Urban form}

Vauban's main street corridor, Vauban Allee is about $35 \mathrm{~m}$ wide, with a street car track and stations situated in the median. However, if one were to consider the urban scale of the project by analyzing a section through its main street in relation to the buildings on both sides, one would expect such a scale to suggest an urban thoroughfare. However, Vauban's policy of limiting cars in the precinct is in contradiction to such a scale. The main street also leads to a dead end on the West of the site, so that the street would not become a vehicular thoroughfare. Such a policy does keep traffic low, but also leads to a cut-off from surrounding neighborhoods. While the clear guidelines for sustainable building leads to interesting and diverse solutions for the house and apartment forms, it is not clear how the ideal of "growth" could be implemented, as Vauban has clear boundaries.

\subsection{Environment}

Vauban displays a complex network of environmentally friendly planning measures. The accumulation of those best practices has some negative effects on the urbanity and connectivity of the new city quarter. For example, the rather unattractive, $1 \mathrm{~m}$ deep infiltration trench for storm water runs for the whole 
length of the boulevard and not only adds $4 \mathrm{~m}$ to its dimensions, but also exacerbates the exchange between the two boulevard sides. One keeps wondering why functions cannot be overlaid and stormwater led to infiltration areas in the numerous public green spaces of the quarter. It appears that these eco-technologies and practices have to be further studied in their effects on urban space.

\subsection{Public Space}

The most successful public spaces in Vauban are the small-scale residential streets, which are car-reduced zones, and function as children's play areas. These streets act like extended front porches, and are often meeting places of neighbors, and provide a good sense of public safety. However, as one moves towards the scale of the main street and the arcaded walkways, a real sense of urbanity is lacking in its public space. Whereas the abundant linear green parks are heavily populated by children, the oversized main street that would have offered the opportunity of a vibrant street life is fairly vacant in the middle of the quarter. It also seems as though there is a lack of critical mass of population to make these lively areas. The scale and nature of the public space at Alfred-Döblin-Platz as it now stands, seem too wide, with little opportunity to linger around except for the beer garden on one end of the square. The temporal space of the market square on Paula-Modersohn-Platz, if adjacent to this square, could have shared the synergy of activity.

\section{Conclusion}

Vauban presents itself as a viable and real alternative to sub-urbanization of neighborhoods and the loss of the sense of urbanism and citizenship in residential developments. Without a preconceived model of architectural typology or urbanism, Vauban is a bold experiment in the planning and design of housing for the future, and bringing back the qualities of the city into neighborhood developments, yet at the same time seeking alternatives such as limiting but not prohibiting car-use by making such a need almost non-existent. Despite the open questions, the case study of Vauban allows us a glimpse of possible alternatives to urban neighborhood development, which allows flexibility for change, yet not depleting the resources for future generations to come.

\section{References}

[1] Gauzin-Müller, D., Sustainable Architecture and Urbanism. Birkhäuser: Basel, 2002.

[2] European Union - LIFE, Building for LIFE Case Study: Vauban Freiburg, Online. http://ec.europa.eu/environment/life/home.htm

[3] Glatz, B. (Stadtteilverein Vauban). Personal interview with the authors 6 July 2006. 
[4] The following are main sources for Ideas and Ideals and Tools and Implementation: Disch, R. (Architect of Solarsiedlung). Personal interview with the authors 5 July 2006; Forum Vauban. Das LIFEProjekt, in: Forum Vauban June 2006 Online. http://forum vauban.de/life.shtml; Fabian, T. (Stadtplanungsamt Freiburg). Personal interview with the authors 5 July 2006; Jehle, S., Quartier Vauban: Vom Planen und Entstehen neuen Wohnbaulandes auf 38 Hektar ehemals französischem Kasernengeländes. Freiburg: Landesentwicklungsgesellschaft Baden-Württemberg and Bauverwaltungsamt der Stadt Freiburg, 1999; Schubert, M. (Stadtteilverein Vauban). Personal interview with the authors 6 July 2006; Sperling, C., 2003. Sustainable Urban District Freiburg-Vauban, in: Forum Vauban, Online. http://forum-vauban.de/overview.shtml 